\title{
Determination of Nigerian Geoid Undulations from Spherical Harmonic Analysis
}

\author{
A. A. Okiwelu (Corresponding author) \\ Geophysics unit, Department of Physics \\ University of Calabar, Nigeria \\ Tel: 234-803-400-3637Ｅ-mail: okiwelu2000@yahoo.com \\ E. E. Okwueze \\ Geophysics Unit, Department of Physics \\ University of Calabar, Nigeria \\ Tel: 234-803-543-2338_E-mail: emeka_okwueze@yahoo.com
}

\author{
I. O. Ude \\ Geophysics Unit, Department of Physics \\ University of Calabar, Nigeria \\ Tel: 234-803-283-2425Ｅ-mail: udeikechi@yahoo.com
}

Received: February 12, 2011 Accepted: February 22, 2011 doi:10.5539/apr.v3n1p8

\begin{abstract}
Geoid undulation has been determined for Nigeria in order to demonstrate its relationship with topography and the dynamic structure of the Earth's interior. Spherical harmonic expansion using the Earth Gravitational Model 2008 (EGM2008) referenced to the WGS84 (World Geodetic System 1984) with coefficients extending to degree 2190 and order 2159 was found suitable for the determination of geoid undulation. The results from the analysis show that the Nigerian geoid undulations are positive and show overall good correlation with topography. The internal origin of the geoid undulation is attributed to excess mass beneath the ellipsoid. This internal mass distribution extend deep into the mantle. The highest geoid undulations are centered over the North central region of Nigeria with relatively lower values confined to the Nigerian sedimentary basins. The lowest geoid undulation values are within the oceanic areas.
\end{abstract}

Keywords: Geoid, Ellipsoid, Undulation, Harmonic, Equipotential, Gravitational

\section{Introduction}

Geophysical and geodetic applications require two equipotential surfaces which closely approximate the figure of the earth. They are the reference ellipsoid which is a geometric mathematical reference surface and the geoid, the equipotential surface that mean sea level follows. These equipotentials are closely associated with gravity. While the ellipsoid is a mathematical convenience, the geoid manifests the true distribution of masses in the interior of the earth and differs from the reference ellipsoid by small magnitude (Li and Gotze, 2001). Mountains, ocean basins and changes in crustal thickness contribute to the observed irregular shape and gravity field of the earth but they do not explain the long-wavelength departure from a hydrostatic figure. The long-wavelength features of the geoid are probably due to density variations in the lower mantle and resulting deformations of the core mantle boundary and other boundaries in the mantle (Richards and Hager, 1984). The reference surface for orthometric heights is a level surface of the earth that is closely associated with mean sea level on a global basis. This particular surface is called the geoid (Milbert and Smith, 1996). While the geodesist uses the geoid to define the shape of the earth, the geophysicist uses the geoid to obtain gravity anomalies in order to learn about the density variations of the earth interior. The main function of the geoid in physical geodesy is to serve as a reference surface for leveling. In leveling, the geodesist measure elevation above or below the geoid. This 
measurement is done to obtain the shape of the geoid and then define the shape of the earth (Anderson, 1989). To accomplish this task, gravity data is required.

Li and Gotze (2001) pointed out that the difference in purpose between geodetic and geophysical application determines a difference in the way to correct observed data and to understand resulting anomalies. They also opined that mean sea level is not quite a surface of constant potential due to dynamic processes within the ocean and that the actual equipotential surface under continents is warped up by the gravitational attraction of the overlying masses. The gravity and geoid anomalies at any location on the earth are calculated by summing the contributions of the spherical harmonic coefficient from all degrees. Bowin (1985) using ratio of gravity to geoid anomalies $(\mathrm{g} / \mathrm{N})$ opined that mass anomalies that exist in the earth at great depth is best represented in the coefficients of low degree spherical harmonics. He also attributed the origin of the earth's largest geoid anomalies to the mass anomalies at the core mantle boundary region. He however, opined that when this core-mantle boundary mass-anomaly contribution to the earth's long wavelength potential field is subtracted from the earth's degree-10 field, a group of spherical harmonic coefficients is discovered that define narrow binds of positive geoid anomalies. These mass anomalies coincide with sites of plate convergence and therefore may be an important driving force for plate tectonics.

The geoid undulation ranges from $-107 \mathrm{~m}$ to $85 \mathrm{~m}$ worldwide relative to the WGS84 (World Geodetic System1984). Geoid height (undulation) is applied to the study of regional and global problems, for example, dynamic structure of the Earth's interior. The anomalous results obtained from surface gravity measurement may be due to earth's density variation or topography features (Cazenave, 1995). One of the ways to ascertain whether the anomalous result is due to density variation or topographic effect is to determine the shape of the earth and this task require the knowledge of the geoid. The range in geoid undulations in addition to its considerable magnitude relates its complexities to topographic relief, sub-surface rock density variations in the interior of the earth (Lowrie, 2007). Therefore, the objective of this study is to demonstrate the relationship between geoid undulation and topography and make some inference on the mass distribution of the interior of the earth underlying Nigeria. This approach serves as an alternative way of studying the earth interior in Nigeria. Most studies have relied heavily on potential field, for example [Ugbor and Okeke (2010), Okiwelu et al., (2010), Osazuwa etal.,1992), Okereke (1988), Okiwelu etal., (2011)] and seismic exploration. To achieve the stated objectives, spherical harmonic analysis becomes handy because spherical harmonic functions are used for describing the variations of geoid height and potential fields with latitude and longitude on the surface of the earth. Large scale features of the geoid are expressed by spherical harmonic expansion of the gravitational potential. The geoid undulations determined in this study if supplemented with a careful GPS (Global Positioning System) survey measurement will be useful for the determination of orthometric height which is usually sought for by the geodesist.

\section{Research Method}

Spherical harmonics analysis is suitable in approximating the shape of the geoid. The geoid is a surface of constant gravitational and centrifugal potential (Anderson, 1989; Cazenave, 1995). For the gravitational potential $U$ the Laplace equation is written in Cartesian coordinates $(x, y, z)$ as

$$
\frac{\partial^{2} U}{\partial x^{2}}+\frac{\partial^{2} U}{\partial y^{2}}+\frac{\partial^{2} U}{\partial z^{2}}=0
$$

In spherical polar coordinate $(r, \theta, \phi)$, the Laplace equation becomes (Lowrie, 2007)

$$
\frac{1}{r^{2}} \frac{\partial}{\partial r} r^{2} \frac{\partial U}{\partial r}+\frac{1}{r^{2} \sin \theta} \frac{\partial}{\partial \theta} \sin \theta \frac{\partial U}{\partial \theta}+\frac{1}{r^{2} \sin ^{2} \theta} \frac{\partial^{2} U}{\partial \phi^{2}}=0
$$

Lowrie (2007) gave the general solution of the Laplace equation for a spheroidal Earth as

$$
U=\sum_{N=0}^{\infty}\left(A_{n} r^{n}+\frac{B_{n}}{r^{n+1}}\right) P_{n}(\cos \theta)
$$

Where $P_{n}(\cos \theta)$ is an ordinary Legendre polynomial of order $n$ and the coordinate $\theta$ is the co- latitude.

For the geoid, the solution of of the Laplace equation varies with azimuth $\phi$ as well as with radius $r$ and $\theta$ and is given by 


$$
U=\sum_{n=0}^{\infty}\left(A_{n} r^{n}+\frac{B_{n}}{r^{n+1}}\right) \sum_{m=0}^{n}\left(a_{n}^{m} \cos m \phi+b_{n}^{m} \sin m \phi\right) P_{n}^{m}(\cos \theta)
$$

Where $P_{n}^{m}(\cos \theta)$ is an associated Legendre polynomial of order $n$ and degree $m$ Equation (4) in a modified form can be written as

$$
U=\sum_{n=0}^{\infty}\left(A_{n} r^{n}+\frac{B_{n}}{r^{n+1}}\right) \sum_{m=0}^{n} Y_{n}^{m}(\theta, \phi)
$$

Where the function

$$
Y_{n}^{m}(\theta, \phi)=\left(a_{n}^{m} \cos m \phi+b_{n}^{m} \sin m \phi\right) P_{n}^{m}(\cos \theta)
$$

is the spherical harmonic function since it has the same value when $\theta$ or $\phi$ is increased by an integral multiple of $2 \pi$. The geoid undulation $N$ (fig.1) is related to the perturbing potential $T$, (Cazenave, 1995) through

$$
N=\frac{T}{g}
$$

Where $g$ is the mean surface gravity. The relationship between the geoid height (undulation) and the ellipsoid height, $h$ is expressed as

$$
h=H+N
$$

Where $H$ is the orthometric height. Geoid height could be beneath the ellipsoid (fig.2). In this case, geoid undulation is negative and the ellipsoidal height is smaller in magnitude than the orthometric height at a given point. A mass outside the ellipsoid, for example, a hill (fig.3a) or a mass excess below the ellipsoid (fig.3b) cause positive geoid undulation. Li and Gotze (2001) expressed the relationship between spherical harmonics degree $m$ and wavelength $\lambda$ of geoid undulation as

$$
\lambda=\frac{2 \pi R}{m} \approx \frac{40,000,000}{m}
$$

Where $R=6371000 m$ is the average radius of the Earth. For a two- dimensional anomaly, an anomaly in geoid with a wavelength $\lambda$ and geoid undulation, the associated gravity anomaly $\Delta g$ is expressed as

$$
\Delta g=\frac{2 \pi \gamma N}{\lambda}
$$

Where $\gamma=980,000 \mathrm{mGal}$ is the average gravity of the Earth.

The EGM 2008 (Earth gravitational Model 2008) by the United States National Geospatial- Intelligence Agency (NGA) development team was used to determine the geoid undulation for Nigeria. This gravitational model is complete to spherical harmonic degree and order 2159 and contains additional coefficients extending to degree 2190 and order 2159. The harmonic degree implies that short wavelength anomalous features can be studied. The EGM2008 is referenced to the WGS84 ellipsoid. The harmonic synthetic program (hsynth WGS84f.) developed by NGA was used to compute the geoid undulation $\left(0.5^{0} \times 0.5^{0}\right)$ for Nigeria. The data set were gridded using a program based on minimum- curvature method (Briggs, 1974) and plotted with a surfer based program.

\section{Results and Discussion}

The EGM 2008 referenced to the WGS84 is very suitable for the determination of geoid undulation because it contains additional spherical harmonic coefficients extending to degree 2190 and order 2159 . This makes the model amenable to the study of wavelengths that the geoid dominate ranging from short (tens of meters) to long (thousands of kilometers). This additional advantage over earlier models implies that the computed geoid 
undulations for Nigeria are invaluable for the study of regional problems such as the dynamics of the Earth interior and the relationship between geoid undulations and topographic features on the Earth surface. The Nigerian geoid undulations (fig.4 and fig.5) are all positive. This result is interpreted to be a combination of two factors: (1) the geoid is affected by the mass of land above mean sea level. That is, elevated area whose centre of gravity is outside the ellipsoid causes an upward attraction leading to local elevation of the geoid above the ellipsoid (fig.3a). (2) The excess mass under the ellipsoid forces equipotential surface to warp upward (Lowrie, 2007). This gives a positive geoid undulation over a mass excess under the ellipsoid (fig.3b). A negative geoid undulation will imply a mass deficit beneath the ellipsoid which will deflect the geoid below the ellipsoid (this is not the case for Nigeria). We therefore, opine that the Nigerian geoid undulation is affected by a combination of uneven topography and heterogeneous internal mass distribution of the Earth and also stress that the heterogeneity extends deep into the mantle. Based on the results from Fig.4 and assertions made above we strongly opine that the geoid undulation show overall good correlation with topographic elevation and dynamic structure of the Earth interior.

The geoid undulation shows a decrease $(16 \mathrm{~m}-20 \mathrm{~m})$ within the Nigerian sedimentary basins (Bornu Basin, Yola Trough) and a further decrease towards the Atlantic Ocean (fig.4). The lower geoid undulations toward the oceanic crust are not surprising because cooling and thermal contraction of the oceanic lithosphere causes depression of the sea floor with age and therefore decrease in geoid height (Aderson, 1989). The geoid undulation gradient between Lagos and Ibadan reflects a transition from oceanic to continental crust. The highest geoid undulations are within the North Central Nigeria with the highest peak centered over Jos Plateau (25m). Topographic elevation in Jos Plateau is over $900 \mathrm{~m}$ while the oceanic areas, Niger Delta and environs range from $0-200 \mathrm{~m}$. The Yola Trough and Bornu Basin have a mean topographic elevation of $300 \mathrm{~m}$. These elevation values and the geoid undulation (fig.4) show good correlation. The positive geoid undulation may be due to temperature and density variation in the interior of the Earth. Dense regions of the mantle that are in isostatic equilibrium generate geoid lows (Hager, 1983). Hot and low velocity regions of the upper mantle generate geoid highs because of thermal expansion and uplift of the surface, while isostatically compensated cold mantle generate geoid lows. In general, hot regions of the lower mantle are associated with geoid highs and mass excess; they therefore, tend to lie along the equator, putting the colder regions of the lower mantle into high latitude (Aderson, 1989). We strongly opine upper mantle origin for the Nigerian geoid undulation because of the heterogeneity of the upper mantle and its distance from the centre of the Earth than the lower mantle and the core. Bowin (1985) is of the opinion that mass anomalies at the core-mantle boundary region contributes significantly to the magnitude of the Earth's largest geoid anomalies. He stressed that the core-mantle boundary may become warped up as a result of stresses developed by motions in the outer part of the core. This implies that mass anomalies that lie in the Earth at great depth is best represented in the coefficients of the low-degree $(\mathrm{m}=2,3)$ spherical harmonics because of their longer wavelength anomalies.

There is a decrease of geoid undulations from $25 \mathrm{~m}$ in Jos Plateau to $21 \mathrm{~m}$ in the Benue Trough. This depression is consistent with the evolution of the trough. The tectonic model involves the rise and cessation of mantle plumes beneath a cretaceous hot spots and attendant patterns of rifting, sedimentation, magnetism and tectonism (Olade, 1975). Earlier suggestion by Wilson (1973) considered the Benue Trough as one of the important hot spots within the Atlantic continental margins. These features are manifested in the final stage in the tectonic evolution of the trough which occurred in the Senonian when mantle upwelling ceased probably due to loss of thermal momentum associated with the death or migration of the thermal plume. This produced subcrustal contraction and a final collapse of the trough which later evolved into a broad asymmetric downwarp (Ajakaiye and Burke, 1973; Olade, 1975). Fairhead and Okereke (1987) are of the opinion that the Benue Trough is part of the West African rift system which was subjected to large tensional stresses leading to rapid crustal stretching and causing surface subsidence. They added that this process is similar to that which took place along the Atlantic margin at the time of continent break up. The decrease in geoid high towards the Nigerian sedimentary basins is also reflected in Calabar Flank and Manfe Embayment. These are all West African marginal basins with similar origin.

\section{Conclusion}

The geoid undulations determined for Nigeria are positive. The geoid highs are caused by uneven topographic masses above the ellipsoid and the excess mass bellow the ellipsoid. The internal mass distribution extends deep into the mantle. The geoid undulations have overall good correlation with topography. The highest geoid undulation values are centered over the North central region while lower values are associated with the Nigerian sedimentary basins with the lowest in oceanic area. The results from this study serves as an alternative approach 
to the study of structure of the Earth's interior and are useful to the geodesist whose interest is in locating geoidal surface which is a reference datum for orthometric height.

\section{References}

Ajakaiye, D. E. and Burke, K. (1973). A Bouguer gravity map of Nigeria. Tectonophysics, 16, 90-103.

Anderson, D. L. (1989). Theory of the Earth. (1 ${ }^{\text {st }}$ ed.). Oxford: Blackwell scientific publishers, (chapter12).

Bowin, C. (1985). Global gravity maps and the structure of the Earth. In W. J. Hinze (Ed.), The utility of regional gravity and magnetic anomaly maps (pp.88-101).Tulsa: Society of exploration Geophysics.

Briggs, I.C. (1974). Machine contouring using minimum curvature. Geophysics, 39, 39-48.

Cazenave, A. (1995). Geoid, Topography and Distribution of Landforms. In T. J. Arens (Ed.), Global Earth Physics: A handbook of Physical constants (pp.32-39). Washinton: American Geophysical Union.

Fairhead, J. D. and Okereke, C.S. (1987). A regional gravity study of the West African rift system in Nigeria and Cameroon and its tectonic interpretation. Tectonophysics, 143, 141-159.

Hager, B. H. (1983). Global isostatic geoid anomalies for plate and boundary layer models of the lithosphere. Earth planetary science letter, 63, 97-109.

Li, X. and Gotze, H. (2001). Ellipsoid, geoid, gravity, geodesy and geophysics. Geophysics, 66 (6), 1660-1668.

Lowrie, W. (2007). Fundamentals of Geophysics ( $2^{\text {nd }}$ ed.). New York: Cambridge University press, (chapter 2).

Milbert, D. G. and Smith, D. A. (1996). Converting GPS Height into NAVD88 Elevation with the GEOID96 Geoid Height Model. [Online] Available: http: // www. Ngs. Noaa.gov/PUBS_LIB/gislis96.html (October, 1996).

Okereke, C. S. (1988). Contrasting modes of rifting: The Benue Trough and Cameroon volcanic line, West Africa. Tectonics, 7 (4), 775-784.

Okiwelu, A. A., Okwueze, E. E., Okereke, C. S. and Osazuwa, I. B. (2010). Crustal structure and tectonics of the Calabar Flank, West Africa, based on residual gravity interpretation. European journal of scientific research, 42 (2), 195-203.

Okiwelu, A. A., Okwueze, E. E. and Obi, D. A. (2011). Specific issues on gravimetric and magnetic methods of geophysical exploration. European journal of scientific research, 48 (3), 399-423.

Olade, M. A. (1975). Evolution of Nigeria's Benue Trough (Aulacogen): a tectonic model. Geological magazine, 112(6), 575-583.

Osazuwa, I. B., Adeniyi,O. O. and Ojo, J. B. (1992). A Gravity study of the older Granite suite in the Zaria Area of Kaduna State. Nigerian Journal of Mining and Geology, 28 (2), 231-236.

Richards, M. A. and Hager B. H. (1984). Geoid anomalies in a dynamic Earth. Journal of Geophysical Research, 89, 5987-6002.

Ugbor, D. O. and Okeke, F. N. (2010). Geophysical investigation in the Lower Benue Trough of Nigeria using gravity method. International journal of physical sciences, 5 (11), 1757-1769.

United States National Geospatial- Intelligence Agency (EGM2008, Released in July 2008). [Online] Available: http://earth- info.nga.mil/GrandG/wgs84/gravitymod/egm2008/index.html (December, 2010).

Wahr, J. (1996). Geodesy and Geophyscis. [Online] Available: http: // Landau. Mines.edu/ Samizdat (July, 1996).

Wilson, J. T. (1973). Mantle plumes and plate motions. Tectonophysics, 19, 149-164. 

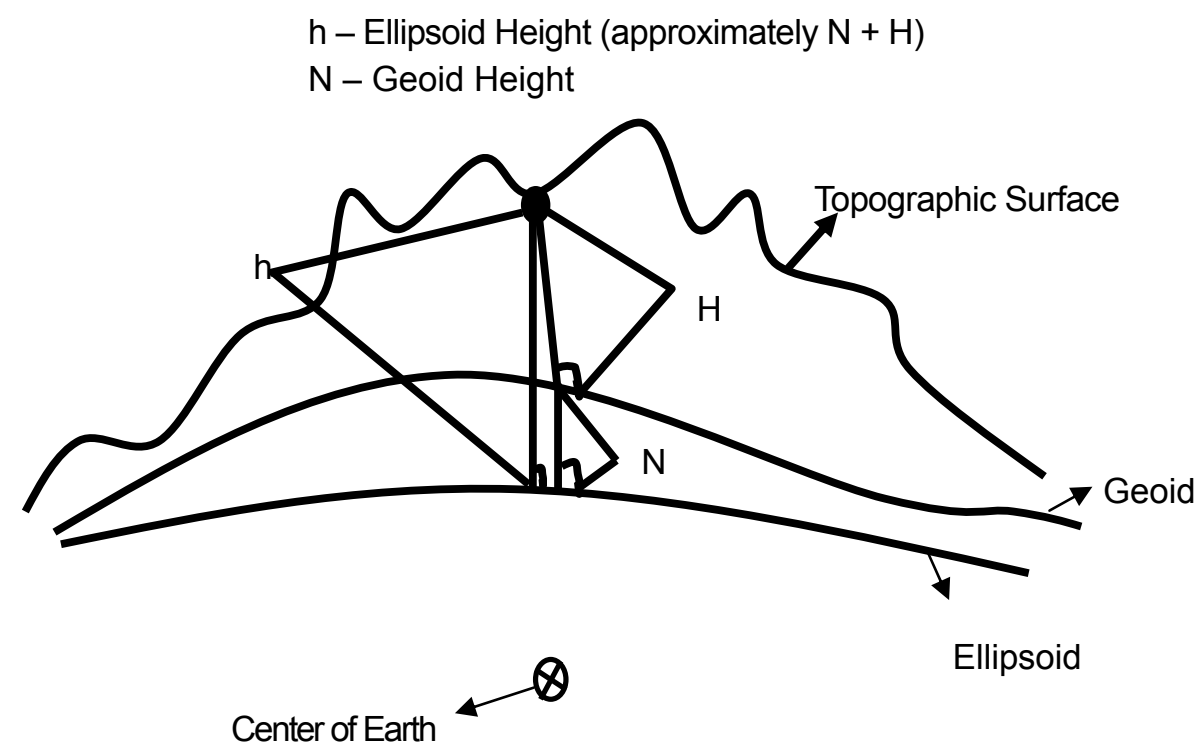

Figure 1. The relationship between ellipsoid height, orthometric height $(\mathrm{H})$ and geoid height

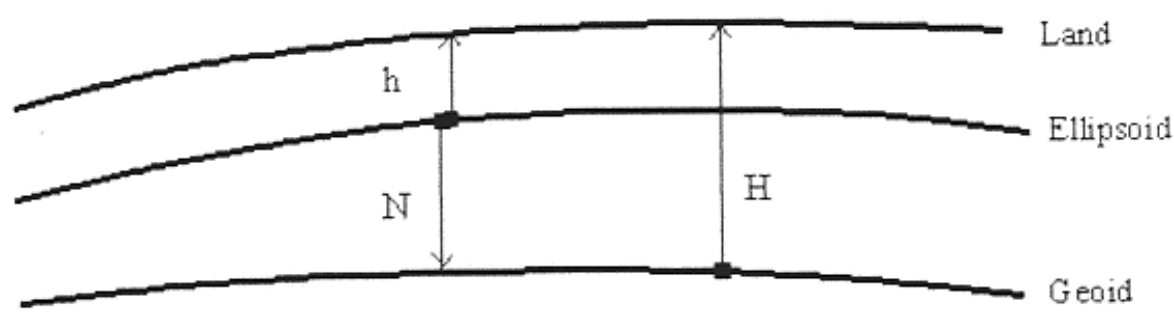

Figure 2. The geoid surface is beneath the ellipsoid
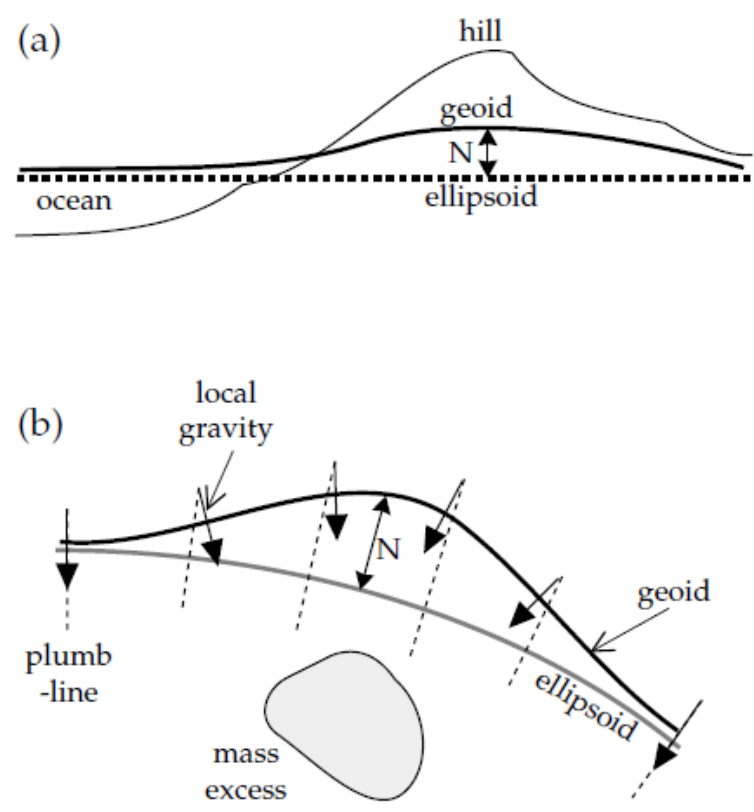

Figure 3. (a) A mass outside the ellipsoid or (b) a mass excess below the ellipsoid elevates the geoid above the ellipsoid. $\mathrm{N}$ is the geoid undulation (Lowrie, 2007). 


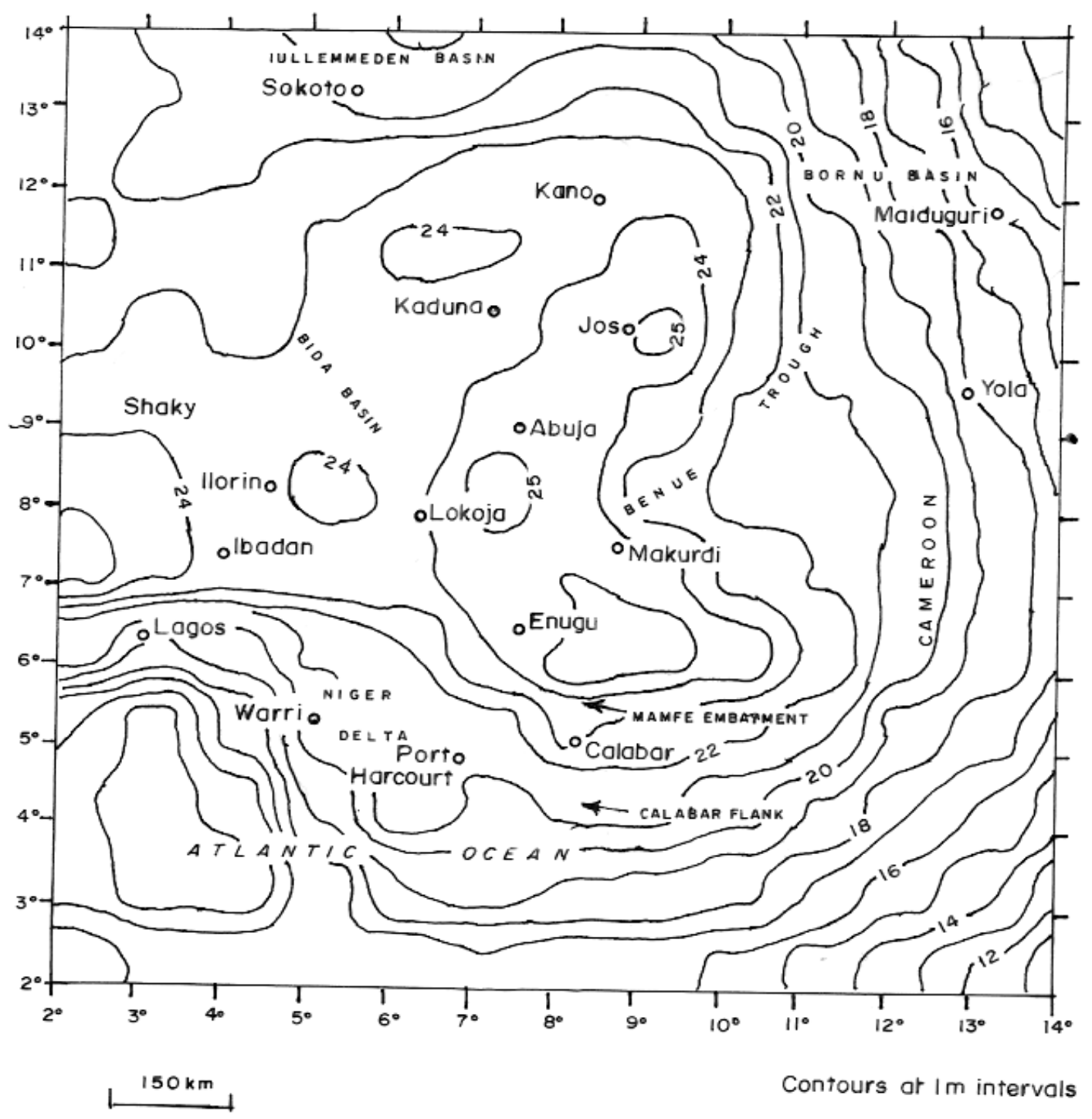

Figure 4. Nigerian geoid undulation determined from spherical harmonic synthesis of EGM2008

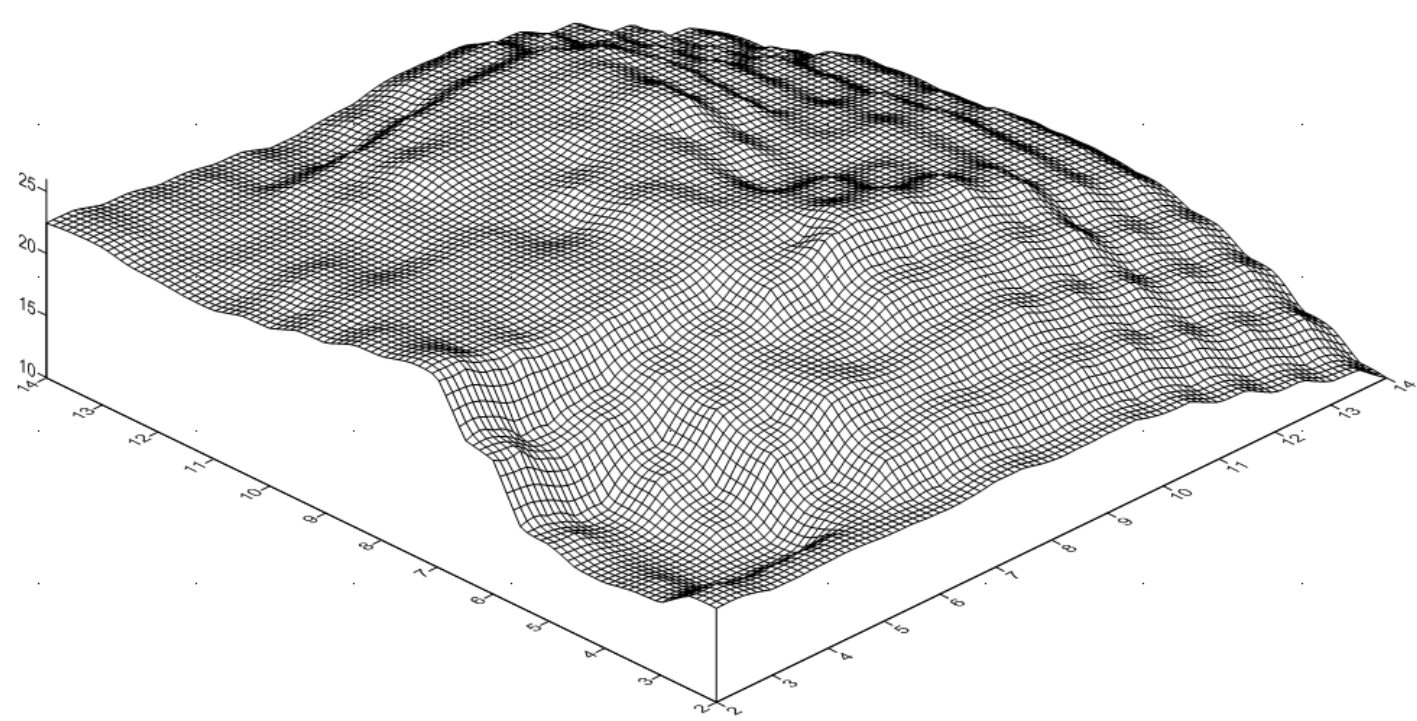

Figure 5. 3-Dimensional view of the Nigerian geoid undulation 